\title{
Neonatal vs. adult sensorimotor cortex damage: The ability to use spared cortical fragments of target tissue to guide tactile learning
}

\author{
DANIEL J. SIMONS and STANLEY FINGER \\ Washington University, St. Louis, Missouri
}

\begin{abstract}
In an earlier study, it was found that rats with little or no sparing of sensorimotor cortex areas SmI and SmII performed extremely poorly on a battery of five tactile discriminations, whether the lesions were made on the 2nd day of life or at maturity. In contrast, infantoperated rats with $13 \%-28 \%$ of the anterolateral part of SmI spared performed better than adult- or infant-operated animals with larger, more complete lesions, although their learning scores were still worse than those of sham-operated animals. In order to determine whether adult-operated rats could use spared fragments of target tissue as well as the infant-operated animals could, lesions sparing $15 \%-31 \%$ of the same regions of sensorimotor cortex were made in mature rats that were subsequently tested for their ability to learn the discrimination problems. The results provide some support for the hypothesis that infant-operated animals can make more efficient use of spared fragments of target tissue than can their adult-operated counterparts even though, in both age groups, animals with subtotal lesions perform better than do animals with almost all or all of the sensorimotor cortex destroyed.
\end{abstract}

Among the factors that can affect the severity of behavioral deficits following damage to the central nervous system (CNS) is an organism's developmental status at the time of insult (Finger \& Stein, 1982). In particular, humans and laboratory animals with brain lesions sustained early in life are often less impaired on behavioral tasks than are matched cases suffering damage after the period of infancy. Nevertheless, there are exceptions to this frequently cited finding, and, in a number of cases, animals with early brain damage have performed as poorly as subjects receiving roughly comparable lesions in adulthood (Johnson \& Almli, 1978). Factors underlying these discrepancies are not entirely understood (e.g., Goldman, 1974), and, to date, relevant hypotheses and theories have not been widely tested for their predictive validity.

In a previous experiment, we examined the effects of sensorimotor cortical lesions made on the 1st day of life on the ability of rats to subsequently make tactile discriminations as adults (Finger, Simons, \& Posner, 1978). The scores of infant-operated rats on a series of five tactile discriminations were found to

This research was supported by National Institute of Neurological Communicative Diseases and Stroke Grant NS-11002 and by the Biomedical Research Support Grant Program, Division of Research Resources, National Institutes of Health. D.J.S. was supported by a grant from the Research and Technology Foundation of the Paralyzed Veterans of America to T. A. Woolsey. D. J. Simons's present address is: Department of Physiology, University of Pittsburgh School of Medicine, Pittsburgh, Pennsylvania 15261 . be highly correlated with the extent of sensorimotor cortex spared by the lesions. Animals with little or no sparing of SmI and SmII were severely impaired in their tactile learning and displayed deficits as pronounced as those of adult-operated rats with equally large lesions. In contrast, infant-operated rats with bilateral lesions that spared more than $10 \%$ of SmI in the anterolaterally situated mouth region performed notably better, although still worse than control animals. To explain these results, it was suggested that this tactile learning was mediated by spared fragments of SmI. It was further hypothesized that infant-operated animals may be better able to use spared fragments of target tissue than are adultoperated animals. Since the adult-operated rats in this study only had near-total or complete lesions of the sensorimotor cortex, it was not possible to make a direct comparison of the effects of sparing more than $10 \%$ of SmI in the two age groups. The present investigation represents a continuation of this research and was undertaken specifically to test the hypothesis that infant-operated rats with lesions that spare sizable fragments of SmI would learn tactile discriminations faster than adult-operated animals with similar subtotal lesions.

\section{METHOD}

\section{Subjects}

Procedures were similar to those described in detail in our earlier study (Finger, Simons, \& Posner, 1978). Thirty sexually mature $(180-\mathrm{g})$ male Sprague-Dawley rats received one-stage bilateral ablations of sensorimotor cortical areas SmI and SmII 
by subpial aspiration. An attempt was made to produce lesions similar to those sustained by the infant-operated rats in the previous experiment, which had $13 \%-28 \%$ sparing of SmI. Typically, this meant leaving intact an area along the anterior and lateral margin of the SmI cortex and, in a few cases, along its most posterior margin as well. The lesions were otherwise intended to include the rest of SmI and all of SmII bilaterally. To prevent the use of visual cues during behavioral testing (see below), the animals were enucleated at the time of surgery; similarly, infant-operated animals from the previous study were enucleated at 90 days of age.

\section{Procedure}

The rats subsequently were tested for their ability to learn the same series of five rough (ridge) vs. smooth tactile discriminations used in the previous study. Eleven animals had postoperative recovery periods of 4 months, which matched those of the infant-operated rats, whereas the remaining 19 animals had recovery periods of 1 month in order to match them to the infantoperated rats in terms of age at the time of testing.

The discriminanda, which were constructed of milled aluminum, formed the floors in two wings of a $\mathrm{T}$-maze, and the rats received a food reward for choosing the correct (rough or smooth) plate. Strict controls were used to prevent the animals from using extraneous, nonvisual cues in the maze (see Finger, Simons, \& Posner, 1978). The animals advanced to more difficult problems after meeting an a priori criterion of a perfect score on one day, preceded by not more than one error in the previous two sessions ( 5 trials/day). The rats were removed from testing after they had successfully mastered all five problems or after they had failed to master any individual problem within 40 days. In the latter cases, the animals were assigned conservative maximum scores ( 43 days to criterion) for that problem and also for the physically more difficult discriminations to which they failed to advance.

\section{Histology}

At the conclusion of behavioral testing the rats were deeply anesthetized with sodium pentobarbital and perfused with $0.9 \%$ saline followed by $10 \%$ Formalin injected through the aorta. Photographs of the dorsal and lateral surfaces of the brain were used to construct drawings of the external boundaries of the lesions. The hemispheres were then flattened and cut on a freezing microtome in $100-\mu \mathrm{m}$ sections that were orientated tangential to the pial surface and parallel to the underlying layer IV (see Walker \& Woolsey, 1974). These sections were stained with thionin and examined for patterns of cellular aggregation in layer IV (i.e., "barrels") that were known to correspond to specific parts of the body representation in SmI (Welker, 1976). An overhead projector was used to trace from serial sections the barrel fields left intact by the incomplete lesions. To arrive at an estimate for the areal extent of SmI remaining in each hemisphere, the tracings were then measured quantitatively by a computer tablet system (Cowan \& Wann, 1973) and compared with similar tracings from intact hemispheres. The SmII lesions were evaluated on the basis of surface topography and their relationships to the SmI lesions.

\section{RESULTS}

The photographs and drawings of the brains of the adult-operated animals were compared on an individual basis with the brains of the infant-operated rats from our previous study. Since the behavioral tasks could be mediated by receptors on either side of the face or body, the hemisphere used for matching the animals was the one containing the greatest amount of spared SmI tissue (the same procedure used previously). No animals with markedly assymetrical lesions were included. Matches were made first on the basis of lesion locus (i.e., cytoarchitectonic zones that could be recognized in the sections) and then on the basis of the lesion extent, as measured quantitatively (see Figure 1). Performance scores were not consulted when the matches were being made.

In analyzing the data, the adult animals were pooled into one group, since the length of the recovery period (1 or 4 months) was not found to be correlated with their performance scores. In addition, animals rewarded for choosing the rough plate were grouped with animals rewarded for choosing the smooth plate, since this also did not affect the learning scores. Furthermore, in tabulating the learning scores of the two age groups, it was necessary to adjust the maximum scores of 2 infant-operated rats (IOB 3 and IOB 7) to 43 days on Problem 5, since they were given 60 days to work on each problem, whereas the adult-operated animals had 40-day limits. Good matches were found for 11 of the infantoperated rats. Table 1 shows the amount of sparing found in these matched pairs, and Figure 2 shows the tactile performance scores of the individuals. As a group, the adult-operated animals averaged 112.3 days ( $S D=70.0)$, and the matched group of infantoperated animals had a mean of 63.0 days to criterion $(\mathrm{SD}=14.0)$. In comparison, the mean number of days to criterion for animals that had received sham operations in infancy in the previous study was 38.58 (see Finger, Simons, \& Posner, 1978).

The data were analyzed in two ways. First, the data were subjected to a repeated-measures analysis of variance (ANOVA) for two groups and five discrimination problems. This analysis was considered to be justified because all of the lesions were roughly comparable, that is, because all spared $13 \%-31 \%$ of SmI in the region of the orofacial representation in at least one hemisphere. The ANOVA revealed a significant group difference in mean number of days to criterion $(p<.05$, one-tail). Since the first and last tasks took longer to master, there was also a task difference $(\mathrm{p}<.001)$, but no interaction effect $(p>.05)$. Second, sign tests were performed on the number of days to criterion so that the performance of individual matched pairs could be evaluated. Eight of the 11 infant-operated rats completed the battery of five discriminations faster than did their matched adult counterparts. Perhaps due to the limited number of matched pairs, however, this test was not statistically significant $(p=.11$, one-tail). Sign tests on each of the five tactile problems showed that, for every discrimination, the performance of the infant-operated rats was better than that of their adult counterparts, although these differences were 


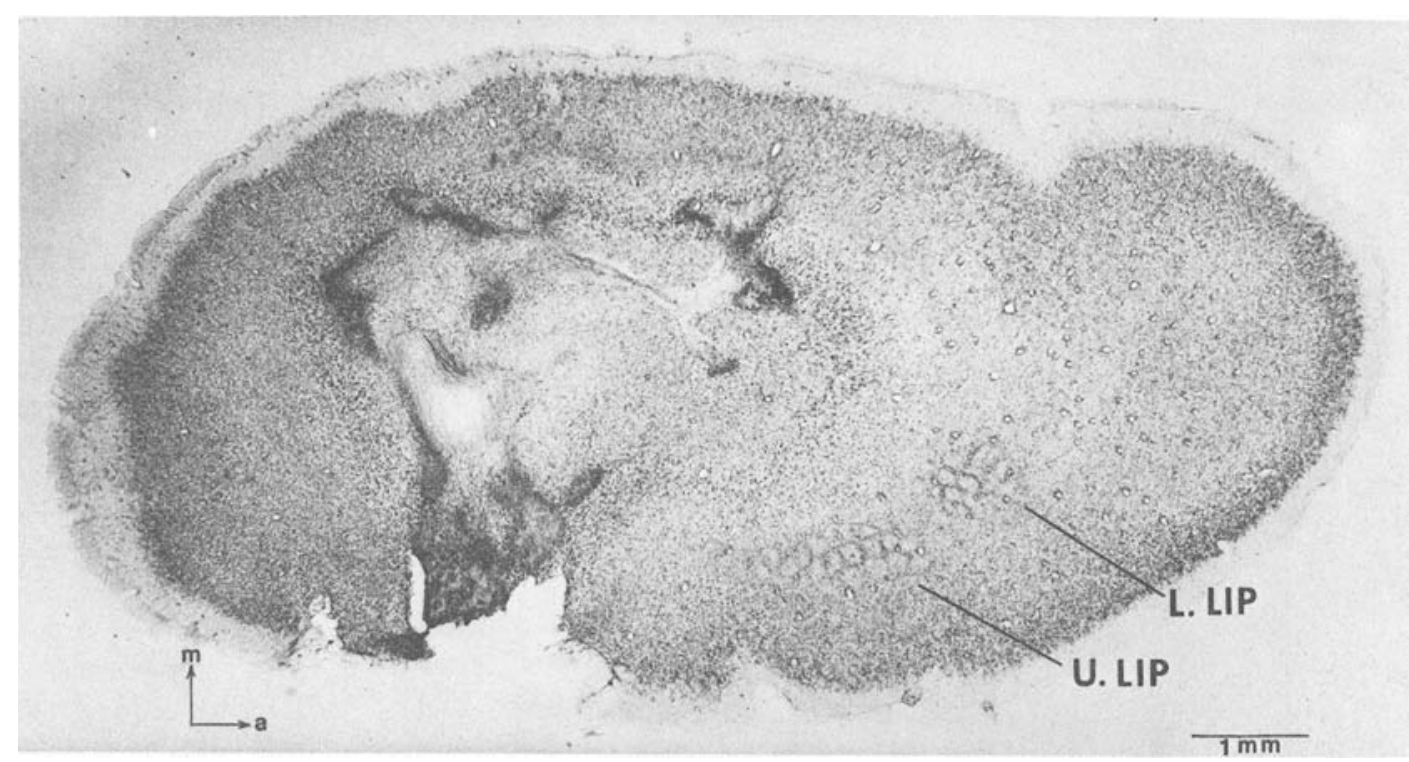

Figure 1. Photomicrograph of a 100- $\mu \mathrm{m}$ thick tangential section through the right cortical hemisphere of an animal (10B) sustaining an incomplete lesion of the SmI cortex. Scar tissues associated with the lesion abcess can be seen in this section along the posterior, medial, and lateral margins of the lesion. Barrels in layer IV were observed only in the anterolateral aspects of the SmI cortex; cellular aggregates corresponding to part of the representation of the upper and lower lip are clearly visible (see Welker, 1976) in this section and in serially adjacent ones (not shown). In this animal, reconstruction of the remaining barrel fields revealed the lesion to be $74 \%$ complete, sparing tissue only in the anterolateral part of the SmI cortex. Compare with Figures 6A and 6B of Finger, Simons, and Posner (1978). Abbreviations: U.Lip-upper lip; L.Lip-lower lip; a-anterior; mmedial.

significant only on Problem 2 ( $p<.05$, one-tail). Thus, although both infant- and adult-operated rats had performance scores well outside a typical controlgroup range of approximately $\mathbf{4 0}$ days to criterion to complete all five problems (see Finger, Simons, \& Posner, 1978), there was reasonable support for the hypothesis that the infant-operated animals could make better use of spared fragments of SmI than could their adult counterparts. This idea was further strengthened by examination of the animals' individual learning scores. The two infant-operated rats that failed to complete the battery (IOB 13 and IOB 16) successfully mastered all but the last discrimination, whereas three adult animals $(8 G, 9 G$, and 10G) were unable to master even the first discrimination in the series.

Despite this difference, it was apparent that both groups of animals were performing better than were rats with considerably less (or no) sensorimotor cortex remaining, regardless of whether the lesions had been made in infancy or adulthood. In the previous study, infant-operated rats with virtually complete lesions of SmI averaged 130 days to complete the battery (adjusted to the 40-day maximum per problem). In fact, 6 of the 10 animals with large lesions failed to complete the series. None of the adultoperated rats that were matched to these animals completed all of the discriminations, and most failed the very first problem. The use of estimated scores for the more difficult discriminations to which these adult-operated animals failed to advance highly inflated the group mean of the adult-operated rats to 167 days to criterion (also based on a 40-day limit).

Anatomical data were carefully scrutinized to determine whether there were any systematic betweengroups differences that could account for the comparatively better learning scores of the infant-operated animals or why three of the infant-operated rats performed worse than their matched adult counterparts did. Differences in the extent of the SmII lesion could be one factor, since the effects of combined SmI and SmII damage may produce more severe deficits than does damage to SmI alone (Norrsell, 1980). Although more difficult to assess than the SmI lesions, SmII damage appeared to be extensive and equivalent among the animals. Specifically, the lesions were continuous with the SmI ablations, which were rostral and medial to them, and they extended ventrally to the rhinal fissure and posteriorly to at least the caudalmost level of the SmI lesions, which for each animal typically damaged the representation of the dorsal vibrissae (Welker \& Sinha, 1972; C. N. Woolsey, 1958).

One unanticipated difference between the two groups that did emerge was in the extent of the SmI lesion in the hemisphere with less sparing, that is, 


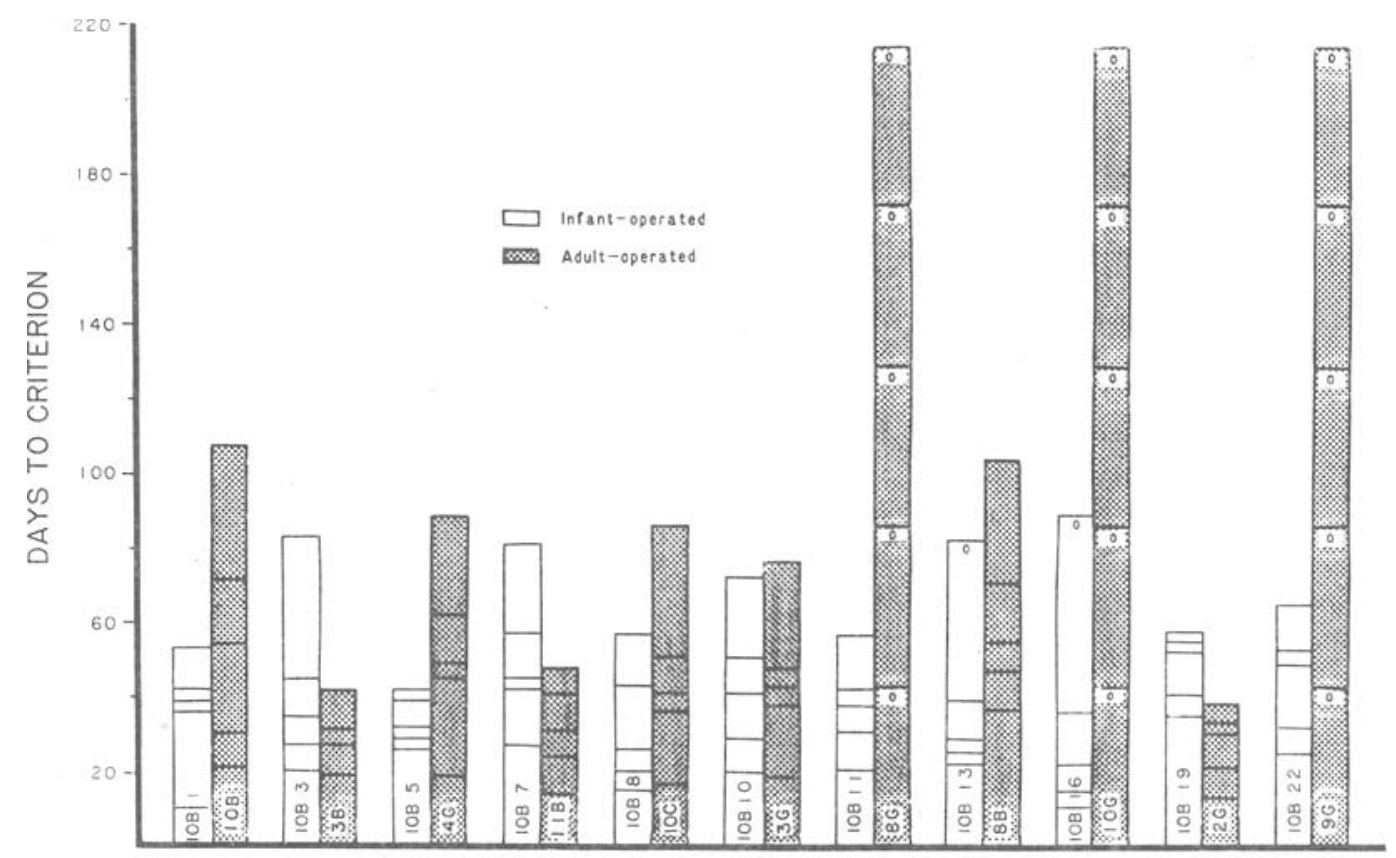

MATCHED LESIONS OF SENSORIMOTOR CORTEX

Figure 2. Days to criterion (vertical bars) for each matched pair of infant- and adult-operated animals on five successive discriminations (horizontal lines through the bars). Circles signify that a discrimination was not mastered within 40 days. Adult-operated animals in Group G had a 120-day recovery period; all other adult-operated rats had 35 -day recovery periods.

the hemisphere not used in making the comparisons. The larger lesion spared an average of $13.9 \%$ of anterolateral SmI in the adults, but only $2.4 \%$ of SmI (same general region) in the infants. Thus, although both groups of animals were comparable on the side with the most sparing $(22.2 \%$ vs. $21.6 \%$ sparing for adults and infants, respectively), the brains were not identical on the opposite side. Since this difference would, if anything, be most likely to favor better performance scores by the adultoperated rats, the fact that the infant-operated rats performed better on the tactile discriminations is that much more noteworthy.

\section{DISCUSSION}

The importance of spared fragments of target tissue in mediating behavior after brain lesions has long

Table 1

Lesion and Performance Data for Anatomically Matched Pairs of Rats With Somatic Cortex Lesions

\begin{tabular}{|c|c|c|c|c|c|c|c|}
\hline \multirow[b]{2}{*}{ Pair } & \multirow[b]{2}{*}{$\begin{array}{l}\text { Regions } \\
\text { Spared }\end{array}$} & \multicolumn{3}{|c|}{ Infant Lesion } & \multicolumn{3}{|c|}{ Adult Lesion } \\
\hline & & Subject & $\begin{array}{l}\text { Percent SmI } \\
\text { Spared* }\end{array}$ & $\begin{array}{c}\text { Total Days to } \\
\text { Criterion }\end{array}$ & Subject & $\begin{array}{l}\text { Percent SmI } \\
\text { Spared* }\end{array}$ & $\begin{array}{l}\text { Total Days to } \\
\text { Criterion }\end{array}$ \\
\hline 1 & $\mathrm{U}, \mathrm{L}, \mathrm{F}$ & IOB 1 & 27 & 53 & $10 \mathrm{~B}$ & 26 & 107 \\
\hline 2 & $\mathrm{U}, \mathrm{L}, \mathrm{F}$ & IOB 3 & 20 & 83 & $3 \mathrm{~B}$ & 17 & 41 \\
\hline 3 & $\mathrm{U}, \mathrm{L}, \mathrm{F}$ & IOB 5 & 21 & 42 & $4 \mathrm{G}$ & 24 & 89 \\
\hline 4 & $\mathrm{U}, \mathrm{L}, \mathrm{F}$ & IOB 7 & 21 & 81 & $11 \mathrm{~B}$ & 22 & 48 \\
\hline 5 & $\mathrm{U}, \mathrm{L}, \mathrm{F}$ & IOB 8 & 19 & 57 & $10 \mathrm{C}$ & 15 & 86 \\
\hline 6 & $\mathrm{U}, \mathrm{L}, \mathrm{H}$ & IOB 10 & 28 & 72 & $3 G$ & 31 & 77 \\
\hline 7 & $\mathrm{U}, \mathrm{L}, \mathrm{F}, \mathrm{D}$ & IOB 11 & 20 & 57 & $8 \mathrm{G}$ & 23 & $215 \dagger$ \\
\hline 8 & $\mathrm{U}, \mathrm{L}, \mathrm{F}, \mathrm{V}$ & IOB 13 & 19 & $82 \dagger$ & $8 \mathrm{~B}$ & 18 & 104 \\
\hline 9 & $\mathrm{U}, \mathrm{L}, \mathrm{F}, \mathrm{V}$ & IOB 16 & 22 & $79 \dagger$ & $10 \mathrm{G}$ & 22 & $215 \dagger$ \\
\hline 10 & $\mathrm{U}, \mathrm{L}, \mathrm{F}$ & IOB 19 & 27 & 58 & $2 \mathrm{G}$ & 29 & 38 \\
\hline 11 & $\mathrm{U}, \mathrm{L}, \mathrm{V}$ & IOB 22 & 13 & 65 & $9 \mathrm{G}$ & 18 & $215 \dagger$ \\
\hline Mean & & & 21.6 & 66.3 & & 22.3 & 112.3 \\
\hline
\end{tabular}

Note $-L=$ lower lip; $F=$ forepaw; $H=$ hindpaw; $U=$ upper lip $; D=$ dorsal head $: V=$ vibrissae.

tUnable to complete all five discriminations (40-day maximum limits). 
been recognized by scientists and practitioners and has even formed an integral part of some major theories of brain function (e.g., Lashley, 1929). Nevertheless, despite a large literature on sensory coding and recovery of function following incomplete lesions (Frommer, 1978), little has been said about those factors that might allow brain-damaged organisms to use spared regions of target tissue to guide behavior. In the present series of experiments, spared fragments were examined in a developmental context. The results provide some support for the hypothesis that organisms suffering brain damage in infancy may be able to make better use of remaining areas of target tissue than can subjects with roughly comparable lesions sustained in adulthood. In contrast, after larger, more complete sensorimotor cortical lesions than those described here, both infantand adult-operated rats display pronounced tactile learning deficits (Finger, Simons, \& Posner, 1978).

Previously, we suggested that the tactile learning observed in infant-operated rats with incomplete SmI lesions was mediated by spared SmI tissue that developed more or less normally after the neonatal ablations. This hypothesis was based principally on our findings that the cytoarchitectonic organization of the remaining SmI cortex appeared to be unaltered and that unit properties such as receptivefield size, locus, and latency in the remaining SmI tissue and in immediately adjacent regions were similar to those in normal, intact animals. Nevertheless, the response to CNS injury, especially in the developing organism, is complex and difficult to assess on any but relatively gross levels (T. A. Woolsey, 1978). Although we cannot at this point directly rule out the possibility that some anatomical and physiological reorganization of the remaining somatic sensory system was responsible for the observed sparing of some tactile behaviors in the infant operates, the most parsimonious explanation for the findings in this and the earlier study may in fact be a behavioral one. That is, an animal that sustains brain damage early in life may be more readily able to adopt different behavioral strategies utilizing remaining components of a functional system than can older animals having well-entrenched habits that are difficult to overcome. For example, in the discrimination tasks used here, the rats could conceivably use their fore- or hindpaws, mystacial vibrissae, and/or perioral sinus hairs. With the forepaw and hindpaw projections severely damaged by the cortical lesions, the younger animals may have learned in the course of development to use their facial hairs to discriminate rough and smooth surfaces. In contrast, as a result of previous learning experiences and learning sets (Harlow, 1949), the adult-operated animals may have tried to use their forepaws for some time after the lesions.
Age at the time of insult may not be the only factor that determines a major role for spared fragments in mediating behavior following brain damage. Several studies from this laboratory have shown that large, but not necessarily complete, lesions of sensorimotor cortex may be associated with rapid tactile learning in adult rats, provided that the lesions are made in two stages rather than all at once (Finger, Marshak, Cohen, Scheff, Trace, \& Neimand, 1971; Finger \& Simons, 1976; Simons, Puretz, \& Finger, 1975). When a lesion is slow-growing, an animal may learn to substitute one set of sensory receptors for another by testing the novel receptor system against a preferred one that is slowly becoming ineffective. Of course, this possibility would be precluded in the case of a lesion of rapid onset. The length of the recovery period also appears to be an important factor in determining how well an animal can use SmI or SmII cortical areas when one or the other is damaged (Finger, Hart, \& Jones, 1982). Experiential factors such as highly "enriched" backgrounds and differential learning histories could also affect how subjects with subtotal lesions use remnants of an altered functional system (Finger, 1978). Prior to a lesion, such animals would have had a greater opportunity than subjects from comparatively impoverished backgrounds to learn that receptor systems can be used in a variety of behavioral contexts, and thus they would be better able to rapidly utilize those components of a sensory system that remain functional after the lesion. Cinematographic analyses of how different groups of animals with comparable subtotal lesions perform behavioral tasks like those used here may be one means of testing these ideas (see Gentile, Green, Nieburgs, Schmeltzer, \& Stein, 1978).

The present study provides one explanation for why subjects with early brain damage have performed better than adult brain-damaged subjects in some studies but not in others. Methodological factors such as the absence or presence of spared target tissue may not, however, be the only variables that account for the divergent results reported in neurobehavioral studies comparing different age groups. In some cases, infant-operated animals have performed tasks better than adults with matched lesions even when an entire CNS area has been damaged (Finger \& Stein, 1982). The nature of the particular neural system involved and/or the developmental status of adjacent, functionally related areas at the time of the lesion may be critical in these instances. Such factors have long been implicated in theories of recovery of function (Munk, 1877; see also Rosner, 1974). Here, too, behavioral variables such as learning histories may be important determinants of how well an individual subject can utilize a CNS mechanism potentially available to him. 


\section{REFERENCES}

Cowan, W. M., \& Wann, D. F. A computer system for the measurement of cell and nuclear sizes. Journal of Microscopy (Oxford), 1973, 99, 331-348.

Finger, S. Environmental attenuation of brain-lesion symptoms. In S. Finger (Ed.), Recovery from brain damage: Research and theory. New York: Plenum, 1978.

Finger, S., Hart, T., \& Jones, E. Recovery time and sensorimotor cortex lesion effects. Physiology \& Behavior, 1982, 29, 73-78.

Finger, S., Marshak, A., Cohen, M., Scheff, S., Trace, R., \& Neimand, D. Effects of successive and simultaneous lesions of the somatosensory cortex on tactile discriminative ability in the rat. Journal of Comparative and Physiological Psychology, 1971, 77, 221-227.

Finger, S., \& Simons, D. Effects of serial lesions of somatosensory cortex and further neodecortication on retention of a rough-smooth discrimination in rats. Experimental Brain Research, 1976, 25, 183-197.

Finger, S., Simons, D., \& Posner, R. Anatomical, physiological, and behavioral effects of neonatal sensorimotor cortex ablation in the rat. Experimental Neurology, 1978, 60, 347-373.

Finger, S., \& Stein, D. G. Brain damage and recovery of function: Research and clinical implications. New York: Academic Press, 1982.

Frommer, G. P. Subtotal lesions: Implications for coding and recovery of function. In S. Finger (Ed.), Recovery from brain damage: Research and theory. New York: Plenum, 1978.

Gentile, A. M., Green, S., Nieburgs, S., Schmeltzer, M., \& Stein, D. G. Disruption and recovery of locomotion and manipulatory behavior following cortical lesions in rats. $\mathrm{Be}$ havioral Biology, 1978, 22, 417-455.

Goldman, P. S. An alternative to developmental plasticity: Heterology of CNS structures in infants and adults. In D. G. Stein, J. J. Rosen, \& N. Butters (Eds.), Plasticity and recovery of function in the central nervous system. New York: Academic Press, 1974.
Harlow, H. F. The formation of learning sets. Psychological Review, 1949, 56, 51-65.

Johnson, D. A., \& Almli, C. R. Age, brain damage, and performance. In S. Finger (Ed.), Recovery from brain damage: Research and theory. New York: Plenum, 1978.

LASHLEY, K. S. Brain mechanisms and intelligence: $A$ quantitative study of injuries to the brain. Chicago: University of Chicago Press, 1929.

Munk, H. Zur Physiologie der Grosshirnrinde. Berliner Klinische Wochenschrift, 1877, 14, 505-506.

Norrsell, U. Behavioral studies of the somatosensory system. Physiological Reviews, 1980, 60, 327-354.

ROSNER, B. S. Recovery of function and localization of function in historical perspective. In D. G. Stein, J. J. Rosen, \& N. Butters (Eds.), Plasticity and recovery of function in the central nervous system. New York: Academic Press, 1974.

Simons, D., Puretz, J., \& Finger, S. Effects of serial lesions of somatosensory cortex and further neodecortication on tactile retention in rats. Experimental Brain Research, 1975, 23, 353-365.

WELKER, C. Receptive fields of barrels in somatosensory neocortex of the rat. Journal of Comparative Neurology, 1976, $163,173-190$.

Welker, C., \& Sinha, M. M. Somatotopic organization of SmIl cerebral neocortex in albino rat. Brain Research, 1972, 37, 132-136.

Welker, C., \& Woolsey, T. A. Structure of layer IV in the somatosensory neocortex of the rat: Description and comparison with the mouse. Journal of Comparative Neurology, 1974, $158,437-454$.

WoolsEY, C. N. Organization of somatic sensory and motor areas of the cerebral cortex. In H. G. Harlow \& C. N. Woolsey (Eds.), Biological and biochemical bases of behavior. Madison: University of Wisconsin Press, 1958.

Woolsey, T. A. Lesion experiments: Some anatomical considerations. In S. Finger (Ed.), Recovery from brain damage: Research and theory. New York: Plenum, 1978.

(Manuscript received December 21, 1982; revision accepted for publication March 8, 1983.) 